\title{
THE CONCEPT OF "OWNING THE CLASS"
}

\section{Plamen Glogov, pglogov@abv.bg}

Institute of Forestry - Bulgarian Academy of Sciences, Sofia, Bulgaria

\begin{abstract}
What does it mean to be a classy person? Does origin or behavior determine whether one is going to be a classy person? Various semantic connotations of the concept of being a classy person are examined in this paper at the level of personality and definion and categorization in terms of basic moral-aesthetic and philosophical principles and concepts has been attempted. In conclusion, being a classy person is presented as a morally independent category, which is associated with an individual's inherent ability to be free from dependence on both material and spiritual stimuli. A classy person will walk away with the same indifference from both heaven and hell. Such a person is a pure emanation of self-overcoming regardless of the ultimate goal.
\end{abstract}

Keywords: class, values, Philosophy of Self-overcoming, ethicя

\section{ПОНЯТИЕТО „АА ПРИТЕЖАВАШ КААСА”}

\author{
П^амен ГАогов, pglogov@abv.bg
}

Институт за гората-Бьлгарска Акалемия на Науките, Софрия, Бьлгария

Резюме: Какво означава еАин човек да притежава „класа"? Произходьт и^и поведението опреАелят класата на мичността? Материальт разглежАа различни смислови конотации на понятието "КАаса" на ниво Аичност и прави опит за неговото десиниране и категоризиране от гледна точка на основни нравствено-естетически и ффилософрски принципи и концепции. ЗакАючението от проучването представя класата като морално и материално независима категория, която е свьрзана с иманентна за личността способност за отказ от зависимост както към материални, така и към Ауховни стимули. Човекьт, притежаващ класа, ще си трьгне с елнакво безразличие и от ала и от рая. Той е чиста еманация на себеналмогването без значение от крайната цел.

КАючови Ауми: к^аса, ценности, Философияя на Себеналмогването, етика. 
Понятието „к^аса” е употребявано най-често в контекста на т.нар. "социална стратифрикация" (Downham, 1954). СпореА Браун (Brown, 2009) названието му произхожла от матинската дума "classis" - разрел, отряд и носи различни конотации спореА реАица изслеАователи и фрилософри като Маркс (Marx, 1954), Вебер (Weber, 2015), Гиленс (Giddens, 1981) и Ар., но с него най-общо се обозначава група от хора (т.нар „стратум”) със сходен социално-икономически статус, ниво на образованост, близки материални и Ауховни цели и интереси, вкА. политически възглели. Настоящият материал разглежла значението на Аумата "к^аса" (от ^атински classicus - „образцов") не в смисьла на обществен слой, а като своеобразна категория, сьдьржаща се в природата на отлелни мичности. Тя е свързана с разпространения често среА всички обществени групи израз „,Аа притежаваш к^аса", т.е к^асата като иманентна особеност - изльчване и сбор от вътрешни качества на човека, с които той може да бъле опрелелен като „притежател" на класа. Франсоа Митеран, Ажаки Кенеди, Франц Бекенбауер, Франк Синатра, Кар^ ^егероре^А - във всички житейски поприща могат $\Delta а$ се открият примери за мичности притежаващи класа. Но кои са критериите, които детерминират това понятие и свързаното с него поведение? Зависи ^и появата му от опрелелени орактори, като възпитание, образование, материална обезпеченост, психическо и ффизическо сьстояние на ИНАИвИАа? Възможно ^и е к^асата $А$ व се приАобие в процеса на АИчностно израстване или е конституирана още от ражАането в субекта? Цел на настоящата разработка е $\Delta а$ отговори на тези и Аруги въпроси и $\Delta а$ хвърли светлина върху смисъла от този тип поведение и ролята на хората притежаващи к^аса в житейски и Ауховен п^ан. Подобно на черната Аупка, която се откроява пасивно - посредством Авижещите се около нея звезди и човекът, носещ в себе си класа, се определя от Аругите около него и по^есно бива типизиран, чрез неговите качества и постьпки спрямо тях. В редица отношения той се припокрива с опрелелението за "аристократа" (от гръцки: "а́рібтєن́s" - благороден произход, елит и „кра́тоS" - власт, моґщество), чийто образ се развива Авуполюсно от социалния вектор и наАхвърля историческата рамка, в която пьрвоначално е очертан. 
В елна научно-описателна енциклопедия от пьрвата половина на миналия век (Penchev, 1941) откриваме следното описание на аристократа: „Истински аристократ не означава $а$ а бъле човек по-учен, по-богат или Аа заема висок Аьржавен или обществен пост. Аристократ означава превьзхожАащ по естеството си човек, който е тих, кротьк, който не обича $л а$ се излага на показ, който не обича да бъле налценяван. Аристократьт не се мисли за по-способен от Аругите, нито извьршва Аела, чрез които се стреми $а$ а докаже на другите някакво свое превъзходство. Той е така наречения "стотен човек”. За него е срамно и пошло Аа бъле наАценяван и хвален от Аругите. Услужливото ^аскателство, което тъй лакомо се погльща от суетните и празните, него го улеснява, а не го ґАеличка. Такъв човек англичаните наричат "Ажентьлмен", което означава благовьзпитан човек, обладаващ следните селем качества: търпение, съчувствие, отсьствие на завист, скромност, Учтивост, себепожертвователност, себеконтрол и великодушие. Който има в себе си тези елементи, независимо от това Аали е пьдар или Аиректор с голяма заплата, такъв човек е Ажентьммен. Той не приказва шумно, нито се смее високо из улиците и кафенетата." Изброените черти и качества на аристократа спокойно биха могли $\Delta$ а се отнесат кьм тези на „човека притежаващ к^аса", като към тях могат Аа бъАат Аобавени още елегантност, изисканост, стил, но също и увереност, и себеуважение (Kinder, 2017), (Jackson, 2020), (Fayed, 2017) и $\Delta$ p.

Във всяка от цитираните по-горе публикации и много Аруги полобни на тях, които изпьлват съвременното интернет пространство, е

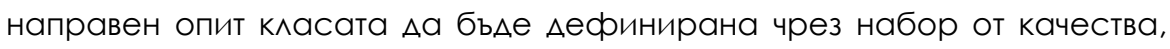
характерни за хората, които я притежават. Но сякаш ^ипсват по-Аьлбоки психологически критерии, изведени на базата на анализ на причините и същността на този тип поведение, а елинствено на резонанса, който то преАизвиква у околните. Той познава различни реакции - от Аьлбоко възхищение, признание и опити това поведение да бъде имитирано и упражнявано изкуствено (в повечето случаи безуспешно) Ао естествена завист и Аистанция от страна на Аругите и крайни изводи като този, че Аемонстрирането на к^аса е белег на психични отклонения като социопатия. 
Ако можем по подобие на Теофрраст (прев. БогАанов (1980)) (Teofrast, 1980) $\Delta$ а възприемем класата като особеност на човешкия характер, тя би могла $а$ а се опрелели като естествено благоролство,

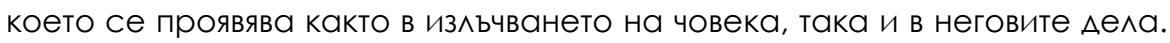
Наистина това изльчване понякога може да се разпознае в поглела на клошаря и да бъле неоткриваемо в целия блясък на богаташа. На вьпроса вролена ли е класата или се прилобива с културата на човека, индиректен отговор намираме още у Светоний (реА. 3^аткова (1981)) (Svetonii, 1981), който описва живота на еАин от най-благородните и Аобродетелни императори Тит ФАавий Веспасиан. Според автора още Аокато Тит би^ м^алеж и учи^ заедно с наслеАника на император КАавлий - Британик, еАин гадател по чертите на лицето, съзирайки го, случайно предрекъ^, че не Британик, а Тит ще бъле император. СпореА Светоний "още като момче у него се появили бляскави телесни и Аушевни Аарования, които С възрастта ставали все по-големи: забележителна сила и красота, в която имало колкото привлекателност, толкова и Аостойнство”. „По природа биА извънреАно благ”, „От никой гражАанин нищо не отнел", "зачитал чужАата собственост както никой Аруг, не приема^ Аори позволените обичайни Аарения", „потвърАи^ правото на потомствени привилегии, като не Аопускал благородниците $А$ व го молят за тях". Тези и реАица Аруги постьпки, много от които са в пряко противоречие с установения протокол и Аори го превъзхожАат морално, показват, че образованието и възпитанието, което придобива Тит (а те за времето си са били на завилно ниво) не са пререквизит за фрормирането на класата в личността му. Те са по-скоро фрактор за нейното развитие, с който нейните критерии и представи могат $А$ се съизмерят, а самата Аичност $а$ a cе себепознае (Hegel, 1806) посреАством приАобитото знание. По $А$ бни изво $А$ могат $\triangle$ व се направят от биографриите на известни Аичности опреАеляни от множеството като носители на естествено благородство и к^аса от близкото и Аалечно мина^о, в това чис^о ^еонарАО Аа Винчи, Ажон ^ок, Вернер Хайзенберг, Василий Кандински и др. Но наред с тези безспорно положителни исторически герои, класата се открива и у ^ичности, чиито имена се преАават на поколенията заеАно с тежките им присьли - личности като Велизарий, Салиери, Робеспиер, Чърчил и др. 
К^асата не е равнозначна на добротата и причината в случая е в несъвършенството на моралните категории "Аобро и з^о" (Nietzsche, 1886), особено в случаите когато се касае за обществени ^ичности и последиците от техните решения. Ако следваме концепцията на Кант (Kant, 1788), която най-общо гАаси, че Аействията на човека са ограничени

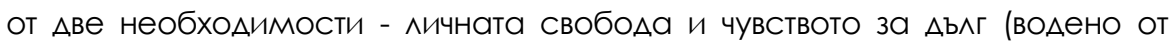
съвестта), които при повечето хора са в непрекъснато противоречие, при ^ичностите притежаващи класа, такова противоречие обикновено няма. Тяхната свобола е в унисон със съвестта им, но за разлика от социопатите, тя е обективна и не поставя егото наА всичко. При това положение философрската концепция, която най-вярно може $а$ обхване и обясни смисьла и поведенческия моде^ на ^ичностите притежаващи класа е Философрията на себеналмогването (Glogov, Glogova and Panorov, 2020), съгласно която смисъльт на съществуването е в нацмогването на егото. Този стремеж не е самоцелен, а е волен от наАличностен императив - социална кауза (на житейско ниво) и подАьржане на висшето енергийно състояние на Сврьхсъзнанието (на Ауховно ниво). При ^ичностите притежаващи класа наАличностният императив съвпала с категоричния императив на Кант (Kant, 1788), (Кант, 1781), съвестта им като неугасващ маяк ги воАи Към Аостойното решение, което те в своята природа притежават силата и волята $\Delta$ а вземат.

Както повечето черти и особености на човешкия характер е възможно и класата да бъде имитирана, доказателство за това са големият брой сполучливо пресъзАалени сценични и екранни образи в киното и театьра от актьори, които в реалния живот са ^ишени от кАаса.

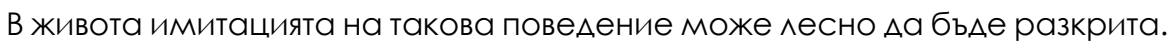
Най-ясно това проличава както в най-Аребните, почти незабележими жестове и поведенчески реакции, така и в екстремните моменти, когато човек излиза извьн зоната на комдрорт и в него се проявяват естествено волята за оцеляване и волята за власт постулирани от Аарвин (Darvin, 1859) и Ницше (Nietzsche, 1922). ЕАин цитат от разказа на О. Хенри (Henri, 1975) "Пьтища" описва много образно това разкриване на псевлоаристократа: "Аицето на Благородният Аолсън мигом се промени - сега на него се четеше студена жестокост, примесена с неумолима алчност. 
От това мице наАникна Аушата на човека - както понякога от прозореца на почтена къща налниква ^ице на злодей". Важно е $а$ се отбележи, че хората определят кой притежава класа и кой не. Затова тази своеобразна титла е субективна. В голяма част от случаите тя вКАЮчва освен Аичностната харизма на човека и силата на неговото Ае^о - отАаленост на обществена кауза и саможертва. По тази причина среА обществените фоигури носещи к^аса у нас са исторически Аичности като Васи^ Аевски, генера^ В^аАимир Вазов, Петьр Аънов, цар Борис III и Ар. Ао съвременни популярни Аичности - артисти и певци като Невена Коканова, Стойчо Мазгалов, Васил Петров, Камелия Тодорова и др. В световен план в това понятие се вк^ючват политически и обществени фоигури като Махатма Ганди, Маргарет Тачьр, Принцеса Ааяна $\Delta о$ актьори (и техните екранни превьпльщения) като Хенри Фонда (сьдебен заседате^ 8 от оилма „12 гневни”), КАинт ИстууА („Аобрият” от „Аобрият, ^ошият и грозният", „Кралицата" Хельн Мирьн (“ЕАизабет II”), Шон Конъри („Агент 007”) и Крис Нот ("Тузарят от „Сексьт и гральт”). В послеАния пример тази еклектика от реални хора и измислени персонажи на прьв поглеА само Аоказва, че хората опреАелят онези измежАу тях, които носят к^асата в себе си и това е в съответствие с втория принцип на Философията на себеналмогването - „ние себеналмогваме чрез Аругите" (Glogov, Glogova and Panorov, 2020).

Зал поведенческия маниер и изльчването на мичностите притежаващи к^аса се крият няколко съществени особености - техните реакции и постъпки могат Аа бъАат обеАинени от еАно правило - „те изглежАа че могат Аа имат всичко, но сякаш не желаят нищо за самите себе си" (нито материални, нито Ауховни облаги). При тези Аичности се наблюАава иманентно по-слаба връзка с егото, отколкото при останалите хора. Аостойнството при тях не е свързано със собственото „Аз", а с налАичностния императив за справеАливост. Затова те рялко отвръщат на Аичните обиАи и напалКи, но са способни на силна реакция, ако бъле накърнено Аостойнството и заплашен животьт на Аругите. Порали отАалечеността си Егото на хората притежаващи к^аса не може $\Delta$ а бъ $\Delta е$ подчинено, не може да бъде изкушено нито от Аоброто, нито от з^ото. 
Пьтят на хората притежаващи класа е като виалукт, по който всеки би могьл $а$ премине, но не всеки може $а$ построи. Минавайки наА света той Аава пьт на много Аруги пьтища под себе си. Краят му е такъв, какъвто е и самият пьт - извисен. Казват, че по стьлбите към гилотината Робеспиер помоли^ палача: "Подайте ми рька! На връщане няма $А$ ви искам тази услуга...". Последната мисъ^ на благородния човек е мисьлта за другите, Аори ако тя е $а$ г ги накара $А$ व се усмихнат. Преди Аа изАьхне в Аома си среА семейството, великият наш съвременник - композиторьт маестро Енио Мориконе беше написал прощални писма на своите роднини и приятели, в които им изказваше благодарност, че е споделил живота с тях.

Вероятно всеки от нас познава личности, които притежават к^аса, възхищава се от тях и се радва на компанията и приятелството им. Може би

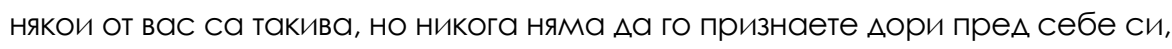
именно защото носите к^аса, която ви кара $\Delta$ а поглежАате отвь - към Аругите. Настоящият материал е опит $\Delta а$ бъде обяснена част от природата на този тип хора, за $А$ б бълат съхранени такива, каквито са. Те са не по-малко застрашени от орлите, които макар и си^ни и реещи се високо в Своя полет имат нужАа от ска^а, на която $А$ кацнат. Ако позволим на пошлостта ни $А$ завлалее земята, те ще уважат решението ни, но ще останат в небето високо наА нас и ще прольлжат $А$ крьжат по своите невилими за нас траектории, докато умрат. Разбрахме, че класата е

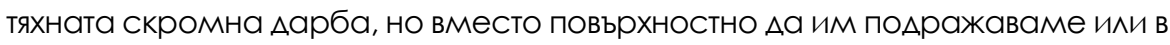
изблик на завист умишлено Аа опитваме Аа ги унищожим, можем $А$ г ги подкрепим в техните инициативи, $а$ в вникнем в принципите, които природата по естествен начин ни разкрива чрез поведението на такива хора, в поуките от решенията, които взимат, защото те са предназначени не за тях самите, а за всички нас. 


\section{LITERATURE ( $\triangle$ UTEPATYPA)}

Brown, D. F., (2009). Social class and Status. In: Mey, Jacob (ed.). Concise Encyclopedia of Pragmatics. Elsevier. p. 952. ISBN 978-0-08-096297-9.

Darvin, Ch., (1859). Proizhod na widovete (translation Hr. Kantardziev) (in Bulgarian). Publisher NARIZDAT, Sofia, Bulgaria, 1946, р. 607. / [Аарвин, Ч. (1859). ПроизхоА на виАовете. (прев. Хр. КантарАжиев). НАРИЗААТ, Софрия, 1946, 607с.]

Downham, J. S., (1954). Social Class in Sample Surveys. The Incorporated Statistician, $5(1), 17-38$.

Fayed, A., (2017). What does it mean to be classy? Quora. https://www.quora.com/What-does-it-mean-to-be-classy

Giddens, A., (1981). The Class Structure of the Advanced Societies. Hutchinson, London. p. 366.

Glogov, P., Glogova, V., Panorov, P., (2020). Sashnost i principi na filosofiata na sebenadmogvaneto (in Bulgarian). Filosofski opiti. University publishing "Neofit Rilski", Blagoevgrad, Bulgaria (15), pр. 90-115. / [ГАогов, П., Глогова, В \& Паноров, P. (2020). Същност и принципи на фрилософрията на себеналмогването. Философоски опити. Университетско изАателство „Неофит Рилски", Благоевграл, (15), 90-115.]

Hegel, G., (1806). Femenologia na duha (translation G. Donchev) (in Bulgarian). Publisher "Iztok-zapad", 2011, р. 632. / [Хегел, Г. (1806) Феноменология на Ауха (превол Г. Аончев). ИзАателство „Изток-ЗапаА", 2011. с. 632.]

Henri, О., (1975). Izbrani razkazi (translation T. Valchev) (in Bulgarian). Publisher "Narodna kultura", p. 507. / [Хенри, О. (1975). Избрани разкази (прев. Т. Вьлчев). Иза. Народна култура. 507 с.]

Jackson, J., (2020). How To Be Classy. 21 Characteristics of an Elegant \& Sophisticated, Woman. Hello Bombshell! https://hellobombshell.com/how-to-be-a-classy-woman/

Kant, I., (1781). Kritika na chistia razum (translation Ceko Torbov) (in Bulgarian). Publisher BAS, 1992, р. 850. / [Кант, И. (1781). Критика на чистия разум. (прев. Цеко Торбов). ИзА. БАН, 1992, 850с.]

Kant, I., (1788). Kritika na prakticheskia razum (translation Ceko Torbov) (in Bulgarian). Publisher BAS, 1993, р. 241. / [Кант, И. (1788). Критика на практическия разум. (превоА: Цеко Торбов). ИзА. БАН, 1993, 241с.]

Kinder, S., (2017). 23 Characteristics of a classy lady. Empowering women now. https://empoweringwomennow.com/23-characteristics-of-a-classy-lady/

Marx, K., (1954). Kapitalat. T. 1 (in Bulgarian). Publisher BKP, Sofia, Bulgaria, p. 808. / [Маркс, К. (1954). Капитальт. Т.1. ИзА. БКП, София, 808 с.]

Nietzsche, F., (1922). Volia za vlast (translation P. Gradinarov) (in Bulgarian). Publisher Zahari Stoianov, 2009, р. 723. / [Ницше, Ф. (1922). Воля за власт. (прев. П. Гралинаров) ИзА. Захари Стоянов, 2009, 723 с.]

Nietzsche, F. (1886). Otvad dobroto i zloto (translation Kileva-Stamenova, P.) (in Bulgarian). Publisher Zahari Stoianov, 2009, p. 254. / [Ницше, Ф. (1886). ОтвъА Аоброто и злото. (прев. Килева-Стаменова, Р.). ИзА. Захари Стоянов, 2009, 254 с.]

Penchev, D., (1941). Nauchno-opisatelna enciklopedia. T. 1 (in Bulgarian). Izdanie na avtora. Printing house "Grafia", p. 168. / [Пенчев, А. (1941). Научно-описателна енцик^опедия. Т.1. Издание на автора. Печатница „Графия", 168 с.] 
Svetonii, (1981). Dvadesette cezari (edited A. Zlatkova) (in Bulgarian). Library "Biblioteka za antichna literatura "Hermes"”, р. 353. / [Светоний (реА. А. 3^аткова) (1981). Аваналесетте цезари. Библиотека за антична литература „Хермес". 353 с.]

Teofrast, (1980). Harakteri (translation B. Bogdanov) (in Bulgarian). Publisher "Narodna kultura", р. 164. / [Теофрраст (прев. Б. БогАанов) (1980). Характери. ИзА. Народна култура.164 с.]

Weber, M., (2015). Classes, Stände, Parties. In: Weber's Rationalism and Modern Society: New Translations on Politics, Bureaucracy and Social Stratification. Edited and Translated by Tony Waters and Dagmar Waters, 37-58.

\section{PLAMEN GLOGOV}

Chief Assistant Dr. pglogov@abv.bg Institute of Forestry - Bulgarian Academy of Sciences Sofia, Bulgaria 

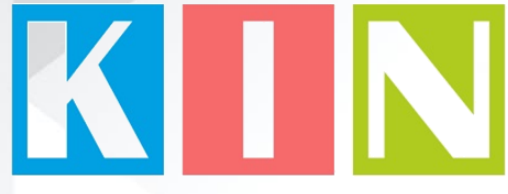

\section{ISSN: 2367-8038}

\section{Съставители \\ Петко Ст. Петков \\ Галина БогАанова}

Материалите в сборника са обект на авторско право. Разрешава се безвъзмезАното ползване на техни електронни/ хартиени копия само за мична употреба или обучение, при пьлно цитиране на текущата страница и слеА писмена Аек^арация от цитиращия за ^ипса на търговски намерения.

Научната поредица е регистрирана в НАЦИА С № 1209

() Авторски колектив, 2021

Техническо реАактори: Калина Сотирова-Вълкова Николай Ноев Паска^ Пиперков

\section{Editors}

Petko St. Petkov

Galina Bogdanova

This work is subject to copyright.

Open and free of charge use of digital/hard copies of publications is granted only for personal or educational use, with full citation of the current page, and after written declaration of the quoting side for notcommercial Intention.

Science series has been registered in NACID with No. 1209

() Authors` Group, 2021

Technical editors:

Kalina Sotirova-Valkova

Nikolay Noev

Paskal Piperkov

\section{ISSN: 2367-8038}

том 7, брой $1(10) / 2021$

vol. 7 , issue $1(10) / 2021$ 